\title{
Permanent Income, Current Income, and Consumption
}

\section{Citation}

Campbell, John Y., and N. Gregory Mankiw. 1990. Permanent income, current income, and consumption. Journal of Business and Economic Statistics 8(3): 265-279.

\section{Published Version}

http://dx.doi.org/10.2307/1391964

\section{Permanent link}

http://nrs.harvard.edu/urn-3:HUL.InstRepos:3353762

\section{Terms of Use}

This article was downloaded from Harvard University's DASH repository, and is made available under the terms and conditions applicable to Other Posted Material, as set forth at http:// nrs.harvard.edu/urn-3:HUL.InstRepos:dash.current.terms-of-use\#LAA

\section{Share Your Story}

The Harvard community has made this article openly available.

Please share how this access benefits you. Submit a story.

Accessibility 
NBER WORKING PAPER SERIES

PERMANENT INCOME, CURRENT

INCOME, AND CONSUMPTION

John Y. Campbel1

N. Gregory Mankiw

Working Paper No. 2436

\author{
NATIONAL BUREAU OF ECONOMIC RESEARCH \\ 1050 Massachusetts Avenue \\ Cambridge, MA 02138 \\ November 1987
}

We are grateful to David Wilcox, and to seminar participants at Duke University, the Federal Reserve Bank of Philadelphia, Harvard University, Rice University and the University of Texas at Austin, for helpful comments on an earlier draft. We acknowledge financial support from the National Science Foundation and the John M. 01 in Foundation at the NBER. The research reported here is part of the NBER's research program in Economic Fluctuations. Any opinions expressed are those of the authors and not those of the National Bureau of Economic Research. 
NBER Working Paper \#2436

November 1987

Permanent Income, Current Income, and Consumption

\section{ABSTRACT}

This paper reexamines the consistency of the permanent income hypothesis with aggregate, post-war, United states data. The permanent income hypothesis is nested within a more general model in which a fraction of income accrues to individuals who consume their current income rather than their permanent income. This fraction is estimated to be 40 or 50 percent, indicating a substantial departure from the permanent income hypothesis. This finding is robust to various statistical problems that have plagued previous work, such as time aggregation, and cannot be easily explained by appealing to changes in the real interest rate or to non-separabilities in the utility function.

John Y. Campbell Department of Economics

Dickinson Hall

Princeton University

Princeton, NJ 08544
N. Gregory Mankiw NBER 1050 Massachusetts Avenue Cambridge, MA 02138 


\section{Introduction}

During the past decade, much effort has been directed at the question of whether the response of consumption to income is consistent with the permanent income hypothesis. Hall (1978) showed that a central implication of the theory is that consumption should follow a random walk. He argued that, to a first approximation, postwar U.S. data are consistent with this implication. In contrast, Flavin (1981) reported that consumption is "excessively sensitive" to income, a conclusion that has been widely interpreted as evidence that liquidity constraints are important for understanding consumer spending (Dornbusch and Fischer, 1987). Yet Mankiw and Shapiro (1985) showed that Flavin's procedure for testing the permanent income hypothesis is severely biased toward rejection if income has approximately a unit root. Nelson (1987) has recently reappraised the evidence on the permanent income hypothesis, and concludes that it is generally favorable.

Other recent research has examined the permanent income theory from a different point of view. Campbell (1987) studies the implications of the theory for savings behavior, while Campbell and Deaton (1987) and West (1986), following Deaton (1986), look at its implications for the "smoothness" (the standard deviation of the change) of consumption. These papers argue that while some of the qualitative implications of the model are fulfilled, consumption appears to be too smooth and there is weak evidence that saving moves too little to be consistent with the theory.

The first goal of this paper is to provide a simple framework for understanding these disparate results. We nest the permanent income 
hypothesis in a more general model in which some fraction of income $\lambda$ accrues to individuals who consume their current income, while the remainder $(I-\lambda)$ accrues to individuals who consume their permanent income $^{1}$. We show that a value of $\lambda$ greater than zero can generate excess sensitivity of consumption to income in the sense of Flavin and insufficient variability of saving as found by Campbe1l. It may also imply excess smoothness of consumption if the stochastic process generating income is highly persistent.

We show how to estimate $\lambda$ and test the permanent income hypothesis that $\lambda=0$, using an instrumental variables approach. Our test is valid whether or not income has a unit root, and it is more powerful than the standard unrestricted test for consumption following a random walk. By lagging our instruments two periods, we are able to avoid econometric difficulties which would otherwise be created by time aggregation of our data. We also show how to test our framework against an even more general time-series representation for consumption and income, for example a disequilibrium "error-correction" model of the type proposed by Davidson, Hendry, Srba and Yeo (1978) and Davidson and Hendry (1981).

The second goal of this paper is to generalize the above approach to handle alternative versions of the permanent income hypothesis. We can allow for changes in the real interest rate, as in Grossman and Shiller (1981), Mankiw (1981), Hansen and Singleton (1983), Bean (1986) and Hall (1987). We can also allow for non-separability in the utility function between consumption and other goods. Following previous work, we examine

1 This model has also been studied by Häl and Mishkin (1981), Hayashi (1982), Summers (1982) and DeLong and Summers (1986). 
interactions with labor supply (Mankiw, Rotemberg and Summers 1985, Bean 1986, Eichenbaum, Hansen and Singleton 1987); durable goods (Bernanke 1985, Startz 1986); and government purchases (Bailey 1971, Kormendi 1983, Aschauer 1985, Bean 1986). We examine whether these alternative formulations of preferences can explain the apparent excess sensitivity of consumption to income.

The organization of the paper is as follows. Section 2 describes our model and instrumental variables test procedure in more detail, and relates our approach to the existing literature. Section 3 reports empirical results for the basic model. Section 4 presents some Monte Carlo results to shed light on the finite sample properties of our tests. Section 5 extends the model to allow for the effects of time-varying real interest rates and nonseparabilities in the utility function. Section 6 concludes. 


\section{An Instrumental Variables Approach to the Permanent Income Hypothesis}

Consider an economy in which there are two groups of agents, who receive income $Y_{1 t}$ and $Y_{2 t}$. Total income $Y_{t}$ is just the sum of the income of these two groups: $Y_{t}-Y_{1 t}+Y_{2 t}$. We assume that the first group receives a fixed share $\lambda$ of total income ${ }^{2}$, so $Y_{1 t}-\lambda Y_{t}$ and $Y_{2 t}=$ $(1-\lambda) \mathrm{Y}_{\mathrm{t}}$.

Agents in the first group consume their current income, so $\mathrm{C}_{1 t}-\mathrm{Y}_{1 t}$. Taking first differences, $\Delta C_{1 t}=\Delta Y_{1 t}-\lambda \Delta Y_{t}{ }^{3}$. Agents in the second group, by contrast, consume their permanent income: $C_{2 t}=Y_{2 t}^{P}-(1-\lambda) Y_{t}^{P}$. By the argument of Hall (1978), as elaborated in Flavin (1981), we then have $\Delta C_{2 t}=\mu+(1-\lambda) \epsilon_{t}$, where $\mu$ is a constant and $\epsilon_{t}$ is the innovation between time $t-1$ and time $t$ in agents' assessment of total permanent income $\mathrm{Y}_{t}^{\mathrm{P}}$. Since $\epsilon_{t}$ is an innovation, it is orthogonal to any variable which is in agents' information set at time $t-1$.

The change in aggregate consumption can now be written as

(1) $\Delta C_{t}=\Delta C_{1 t}+\Delta C_{2 t}=\mu+\lambda \Delta Y_{t}+(1-\lambda) \epsilon_{t}$.

Our empirical strategy will be to estimate $\lambda$, and test the permanent income hypothesis that $\lambda-0$, by running the regression (1). It is

${ }^{2} \mathrm{Y}$ is defined to include both labor and capital income. One might argue that group one should receive a constant share of labor income, rather than total income. In practice, this difference is probably not important.

3 A slightly more general specification would be that agents in the first group consume a fraction $k$ of their current income. We would then have $k \lambda$ wherever $\lambda$ appears in the equations below. Our estimates of the income share of current-income consumers are biased downwards if these agents have a marginal propensity to consume less than unity. 
important to note, however, that (1) cannot be estimated by Ordinary Least Squares. The error term $\epsilon_{t}$ is orthogonal to lagged variables, but not necessarily to $\Delta \mathrm{Y}_{t}$. In fact, most plausible income generating processes will lead to a positive correlation between the change in current income, $\Delta Y_{t}$, and the revision in agents' forecasts of future income, $\epsilon_{t}$. The correlation will make oLS estimates of $\lambda$ inconsistent and biased upward 4 .

The solution to this problem is to estimate (1) by instrumental variables rather than oLS. Any lagged stationary variables are potentially valid instruments since they are orthogonal to $\epsilon_{t}$ if the model is correct. Of course, good instruments must also be correlated with $\Delta Y_{t}$. If $\Delta Y_{t}$ is completely unpredictable then there are no instruments which are orthogonal to $\epsilon_{t}$ but correlated with $\Delta Y_{t}$, and the procedure breaks down. In this case permanent income and current income are equal so the parameter $\lambda$ is unidentified. More generally, if $\Delta Y_{t}$ is only slightly predictable it will be hard to obtain a precise estimate of the parameter $\lambda$.

Equation (1), estimated by instrumental variables, can be thought of as a restricted version of a more general two-equation system in which $\Delta C_{t}$ and $\Delta Y_{t}$ are regressed directly on the instruments. If we have $K$ instruments, $X_{1 t}$ through $X_{K t}$, then the general system is

4 One can write down special cases in which $\Delta \mathrm{Y}$ and $\epsilon$ are uncorrelated. For example, if $\Delta Y$ is white noise, but consumers know the realization of $\Delta Y$ perfectly one period in advance, then $\Delta Y$ and $\epsilon$ are uncorrelated. There may also be specific shocks - - such as a deficitfinanced increase in military spending, discussed further below - - which raise current disposable income but lower permanent disposable income. Nevertheless, it seems reasonable to assume that an increase in current income is generally associated with an increase in permanent income. 


$$
\begin{aligned}
& \Delta C_{t}=\beta_{0}+\beta_{1} X_{1 t}+\ldots+\beta_{K} X_{K t}+\eta_{C t}=X_{t} \beta+\eta_{C t} \\
& \Delta Y_{t}=\gamma_{0}+\gamma_{1} X_{1 t}+\ldots+\gamma_{K} X_{K t}+\eta_{Y t}=X_{t} \gamma+\eta_{Y t} .
\end{aligned}
$$

The permanent income hypothesis implies that the vector $\beta=0$ (that is, $\beta_{1}=\ldots-\beta_{\mathrm{K}}=0$ ). This can be tested directly, and without any need for predictability of $\Delta Y_{t}$, by OLS estimation of the first equation of (2). But it is hard to interpret a rejection of the permanent income hypothesis in this framework; an estimate of $\lambda$ is much more informative about the economic importance of deviations from the theory. For this reason we focus on instrumental variables estimation of (1).

When there is more than a single instrument, equation (1) places overidentifying restrictions on (2), that predictable changes in consumption and income, and therefore the vectors $\beta$ and $\gamma$, are proportional to one another $\left(\beta-\lambda \gamma\right.$, or $\left.\beta_{1} / \gamma_{1}-\ldots-\beta_{\mathrm{K}} / \gamma_{\mathrm{K}}-\lambda\right)$. If we are to put much weight on the estimate of $\lambda$ that we obtain from (1), it is important to test these restrictions. A simple way to do this is to regress the residual from the instrumental variables regression on the instruments, and then to compare $T$ times the $R^{2}$ from this regression, where $T$ is the sample size, with the $x^{2}$ distribution with $(K-1)$ degrees of freedom. We use this test below.

Equation (1) also implies that for any value of $\lambda$, the $R^{2}$ of the regression of $\Delta C_{t}$ on instruments must be less than the $R^{2}$ of the regression of $\Delta Y_{t}$ on instruments, unless $\epsilon_{t}$ and $\Delta Y_{t}$ are strongly 
negatively correlated ${ }^{5}$. As argued above, there is a presumption that $\epsilon_{t}$ and $\Delta \mathrm{Y}_{t}$ are positively correlated, so we expect to find this ordering of the $R^{2}$ statistics when we estimate the two-equation system (2) by OLS. This reasoning implies that a small $\mathrm{R}^{2}$ for changes in consumption cannot be interpreted as strong evidence in favor of the permanent income hypothesis. If the $\mathrm{R}^{2}$ for changes in income is small, it is very possible that consumption is close to a random walk as measured by $R^{2}$ but the permanent income hypothesis is far from true as measured by $\lambda$.

The choice of instruments is critically important in our approach. Perhaps the most obvious instruments are ones which summarize the history of $Y_{t}$. Flavin (1981) used lagged values of detrended $Y_{t}$ in her test of the mode ${ }^{6}$. Mankiw and Shapiro (1985), however, showed that this leads to statistical problems when the $Y_{t}$ process has a unit root. Lagged values of $\Delta Y_{t}$ are valid instruments but, as we show below, they do not explain a large fraction of the variance of $\Delta Y_{t}$.

Campbell (1987) emphasizes that the history of $C_{t}$ should also provide good instruments for $\Delta \mathrm{Y}_{t}$. This is because, according to the permanent. income hypothesis, $C_{t}$ summarizes agents' information about the future of the $\mathrm{Y}_{t}$ process. If agents have better information about $\mathrm{Y}_{t}$ than is contained in that variable's own history, then $C_{t}$ will help to forecast

5 To see this, note that the $\mathrm{R}^{2}$ in the consumption equation is $\lambda^{2} \operatorname{Var}\left(\mathrm{X}_{t} \gamma\right) /\left(\lambda^{2} \operatorname{Var}\left(\Delta \mathrm{Y}_{t}\right)+(1-\lambda)^{2} \operatorname{Var}\left(\epsilon_{t}\right)+2 \lambda(1-\lambda) \operatorname{Cov}\left(\Delta \mathrm{Y}_{t}, \epsilon_{t}\right)\right)$ which is less than or equal to the $R^{2}$ in the income equation when $(1-\lambda)^{2} \operatorname{Var}\left(\epsilon_{t}\right)+2 \lambda(1-\lambda) \operatorname{Cov}\left(\Delta Y_{t}, \epsilon_{t}\right) \geq 0$.

6 She estimated the system (2) by OLS, and tested the zero restrictions on the coefficients in the consumption equation. However she motivated and interpreted her results using the model (1). 
$Y_{t}$. Furthermore, the permanent income hypothesis implies that $C_{t}$ and $Y_{t}$ are cointegrated so that saving $S_{t}-Y_{t}-C_{t}$ is stationary. Lagged values of $S_{t}$ or $\Delta C_{t}$ are likely to increase the precision with which the parameter $\lambda$ can be estimated.

There is another advantage to using lags of $\Delta Y_{t}, \Delta C_{t}$ and $S_{t}$ as instruments ${ }^{7}$. The unrestricted system (2) which results from this choice of instruments is an error-correction model for consumption and income, of the type proposed by Davidson, Hendry, Srba, and Yeo (1978) and Davidson and Hendry (1981). An error-correction model is an appealing way to summarize the time series behavior of cointegrated variables. Davidson et al. interpret their error-correction models in terms of disequilibrium adjustment of consumption to income; our approach suggests an alternative interpretation, involving forward-looking consumption behavior of at least some agents. As discussed above, our model (1) places testable restrictions on the error-correction framework.

Financial variables are also appealing instruments. There is considerable evidence that changes in stock prices and interest rates help to forecast changes in income (Fischer and Merton 1984, Sims 1980, Litterman and Weiss 1985). Hall (1978) found that stock prices also forecast changes in consumption. We use both stock prices and interest rates in our empirical work.

To conclude this section, we briefly argue that our specification (1) is consistent with the conclusions reached in some other recent work on aggregate consumption behavior. First, we develop the implications of

7 Note that $\Delta S=\Delta Y-\Delta C$, so there is potentially a linear dependence among the instruments. This can be avoided by including only one lag of $S$, and any number of lags of $\Delta Y$ and $\Delta C$. 
(1) for savings behavior and the variability of consumption. According to our model, aggregate saving is given by

(3) $s_{t}=Y_{t}-C_{1 t}-C_{2 t}=(1-\lambda)\left(Y_{t}-Y_{t}^{P}\right)$.

When the permanent income hypothesis holds (that is, when $\lambda-0$ ), then saving equals transitory income, the difference between current and permanent income. As $\lambda$ increases, consumption moves more closely with current income and saving becomes a smaller fraction of transitory income. Thus the model (1) predicts that observed saving is perfectly correlated with its value under the permanent income hypothesis, but that it may have a smaller standard deviation. This implication accords quite well with the results of Campbell (1987).

The effect of $\lambda$ on the smoothness of consumption can be read off from equation ( 1 ). As $\lambda$ increases, $\Delta Y_{t}$ gets greater weight in the consumption change, and $\epsilon_{t}$ gets less weight. Consumption becomes smoother if $\Delta Y_{t}$ is less variable than $\epsilon_{t}$. This will be the case if $Y_{t}$ follows a process which is more persistent than a random walk, in the sense that shocks tend to be amplified rather than damped by the subsequent movements of the series. (An example is $\Delta \mathrm{Y}_{t}=\rho \Delta \mathrm{Y}_{t-1}+\epsilon_{t}$ where $\rho>0$. ) Campbell and Deaton (1987) argue that in postwar U.S. data consumption is smoother than it would be if the permanent income hypothesis were true. The model with $\lambda>0$, in which consumption moves too closely with current income, is one possible explanation for this result ${ }^{8}$.

8 However the model with $\lambda>0$ cannot explain the observation that consumption is smoother even than current income. Other considerations (such as the arguments for moving average behavior of consumption given 
Our model (1) may also be able to account for the finding of Hall (1986) that the response of consumption to contemporaneous changes in military spending is almost zero, even though current income responds positively to these changes. If increased military spending is initially financed by borrowing, with higher taxes coming later, it will raise current disposable income but lower permanent disposable income. In our notation, $\Delta \mathrm{Y}_{t}$ will be positive but $\epsilon_{t}$ will be negative. The positive response of current-income consumers to $\Delta Y_{t}$ could be just offset by the negative response of permanent-income consumers to $\epsilon_{t}$. Hall (1986) is unable to distinguish these effects because he uses a contemporaneous instrument rather than lagged instruments to estimate the response of consumption to income.

in the next section) are required to explain this. Deaton (1986) proposes a habit-formation model (his equation (22)) which is our equation (1) with $\Delta Y_{t}$ replaced by $\Delta C_{t-1}$. 


\section{Empirical Results for the Basic Model}

Before we can estimate our model, we need to address two issues of specification which arise from the nature of the aggregate time series on consumption and income.

Our discussion so far has been couched in terms of levels and differences of the raw series $C_{t}$ and $Y_{t}$. This is appropriate if these series follow homoskedastic linear processes in levels, with or without unit roots. In fact, however, aggregate time series on consumption and income appear to be closer to log-linear than linear. The mean change and the innovation variance both grow with the level of the series. A correction of some sort appears necessary ${ }^{9}$.

Two alternative strategies are available for scaling the variables. One approach is simply to take logs of all the variables in the previous section. Equation (1) should hold in logs, with $\lambda=0$, if aggregate consumption is chosen by a representative agent with a power utility function facing a constant riskless real interest rate (Hansen and Singleton 1983, Bean 1986, Hall 1987, Nelson 1987). The instruments discussed in the previous section remain stationary, but we now use the difference between $\log$ consumption and $\log$ income, the $\log$ consumptionincome ratio, rather than saving. The only problem with this approach is that the parameter $\lambda$ can no longer be precisely interpreted as the fraction of agents who consume their current income; however, if one is willing to approximate the $\log$ of an average by an average of logs, the interpretation of the model is not substantially affected.

9 Hall (1978) did not scale his variables. Nelson (1987) shows that this has some effect on the results he obtained, although Hall's general conclusions are not sensitive to scaling. 
An alternative scaling method is to divide $\Delta C_{t}$ and $\Delta Y_{t}$ by the lagged level of income, $Y_{t-I}$. Campbell and Deaton (1987) derive a linear approximation to the permanent income model which uses this approach. The instruments can be scaled in the same way. In practice both scaling methods give very similar results, so we report only results for logs below ${ }^{10}$. We use lower-case letters to denote log variables.

A second data problem is that consumption and income are measured as quarterly averages rather than at points in time. If the permanent income hypothesis holds in continuous time, then measured consumption is the time average of a random walk. The results of Working (1960) imply that it will have a first-order serial correlation of 0.25 , which could lead us to reject the model even if it is true. Christiano, Eichenbaum and Marshall (1987) and Hall (1987) argue that a continuous-time version of the permanent income model fits postwar U.S. data better than a discrete-time version.

We deal with this problem by lagging the instruments more than one period, so that there is at least a two-period time gap between the instruments and the variables in equation (1). The time average of a continuous-time random walk is uncorrelated with all variables lagged more than one period, so by using twice-lagged instruments we obtain a

10 The main difference is that the second method gives slightly smaller (but no less statistically significant) estimates of the parameter $\lambda$. The reason for this is that in the first method, the left hand side of (1) is approximately $\Delta C_{t} / C_{t-1}$, while in the second method it is $\Delta C_{t} / Y_{t-1}$. $C_{t_{-1}}$ is smaller than $Y_{t-1}^{t}$, Both because the mean of saving is positive and because we use only nondurables and services consumption, a fraction of the total, in our tests. 
test of the model that is valid for time-averaged data ${ }^{11}$.

Tie extra lag in the instruments also helps meet several other potential objections. First, Goodfriend (1986) has noted that aggregate variables are not in indfviduals' information sets contemporaneously because of delays in government publication of aggregate statistics. Since such delays are typically no more than a few months, lagging the instruments an extra quarter largely avoids this problem ${ }^{12}$. Second, it is sometimes suggested that those goods labelled non-durable in the National Income Accounts are in fact partly durable. Durability would introduce a first-order moving average term into the change in consumer expenditure (Mankiw 1982); this would not affect our procedure using twice-lagged instruments. Third, there may be white noise errors in the levels of our consumption and income variables. These could be due to "transitory consumption", or to measurement errors. White noise errors in levels become first-order moving average errors in our differenced specification, and could be correlated with once-lagged instruments; but they cannot be correlated with twice-lagged instruments.

These arguments for twice-lagging our instruments also imply that the error terms in equations (1). and (2) have a first-order moving average structure. If we ignore this and use standard oLS and instrumental variables procedures, the coefficient estimates remain consistent but the

11 Another response to the time-averaging problem would be to use monthly data at quarterly intervals. Nelson (1987) uses this approach. However we found that the results we obtained were somewhat sensitive to whether we used first-month, middle-month or last-month data from each quarter.

12 The problem is not completely avoided, since the data are revised over a long period of time. Below we use as instruments financial variables such as nominal interest rates, which are known contemporaneously, and this fully circumvents the problem. 
standard errors are inconsistent. Fortunately, a straightforward standard error correction is available (White 1984); White's methods can also be used to allow for conditional heteroskedasticity in the error terms of (1) and (2). For our data, these corrections make almost no difference and we report uncorrected standard errors below ${ }^{13}$.

To estimate our model, we use standard U.S. quarterly time series data, obtained from the Data Resources, Inc. data bank. $Y_{t}$ is measured as disposable income per capita, in 1982 dollars. $C_{t}$ is per capita consumption of nondurables and services, in 1982 dollars. The data are available from 1948:1 through 1986:4, but we end our sample in 1985:4 in order to avoid using highly preliminary 1986 data. We begin our sample either in 1953:1, the date used by Blinder and Deaton (1985), Campbell (1987) and Campbell and Deaton (1987), which avoids the Korean War, or in 1949:1, the earliest date which allows us to include instruments lagged up to two years. The 1949:1 starting date corresponds more closely to the empirical work of Hall (1978), Flavin (1981) and Nelson (1987).

Table 1 reports results for the 1953:1-1985:4 sample period. The table has six columns. The first gives the row number and the second the instruments used ${ }^{14}$. The third and fourth columns give the adjusted $R^{2}$ statistics for OLS regressions of $\Delta c_{t}$ and $\Delta y_{t}$, respectively, on the instruments. In parentheses we report the $p$-value for a Wald test of the hypothesis that all coefficients are zero except the intercept. The

13 Taking account of the moving average error structure tends to reduce the reported standard errors very slightly; taking account of heteroskedasticity tends to increase them very slightly.

14 A constant term is always included as both an instrument and a regressor, but is not reported in the tables. 
fifth column gives the instrumental variables estimate of $\lambda$, with an asymptotic standard error. The final column gives the adjusted $R^{2}$ statistic for an OLS regression of the residual from the instrumental variables regression on the instruments. In parentheses we report the pvalue for the corresponding test of the overidentifying restrictions placed by equation ( 1 ) on the general system (2). This test can only be carried out when more than one instrument is used.

The first row of Table 1 shows the coefficient obtained when we estimate equation ( 1 ) by OLS. The coefficient is about 0.33 (and the $\mathrm{R}^{2}$, not reported in the table, is also about 0.33 , which means that the variance of consumption growth is one third the variance of income growth). The remaining rows give instrumental variables results for various choices of instruments. In all cases we include at least lags two through four of the instruments ${ }^{15}$; in some rows we add lags five and six, for a total of five instruments.

Rows 2 and 3 of the table use lagged income growth rates as instruments. These are not strongly jointly significant in predicting consumption or income growth; in row 3 , for example, lags two through six of income growth are jointly significant at the $16.5 \%$ level for consumption growth and at the 6.28 level for income growth. Nevertheless, we estimate $\lambda$ at 0.477 with an asymptotic standard error of 0.151 in this row. The corresponding $t$ statistic is 3.15 , with a

15 When we included only the second $\mathrm{lag}$, we found that it was not possible to forecast either consumption or income growth at conventional significance levels. 
significance level of $0.28^{16}$. The instrumental variables procedure therefore rejects the permanent income hypothesis much more strongly than the OLS test for joint significance of the instruments in predicting consumption growth. This pattern is found consistently throughout the table.

Stronger results are obtained in rows 4 and 5 of the table, where we use lagged consumption growth rates as instruments. It is striking that lagged consumption forecasts income growth more strongly than lagged income itself does, and this enables us to estimate the parameter $\lambda$ more precisely. It is estimated at 0.526 in row 5 (with a $t$ of 4.17 , significant at less than the 0.18 level). The oLS test also rejects the permanent income model in row 5.

We next consider using some financial variables as instruments. We tried using lagged changes in real stock prices (the quarterly percentage change in the real value of the Dow Jones Industrial Average), but found that this variable had no predictive power for consumption growth or income growth ${ }^{17}$. Results using lagged changes in quarterly average 3month nominal Treasury bill rates $\left(i_{t}\right)$ were much more successful, and we

16 Close inspection of the regressions underlying row 3 shows that the fifth 1 ag of income growth predicts both consumption growth and income growth (with a $t$ statistic of -2.25 for consumption, and -2.20 for income). This fact presumably accounts for the strong rejection of the permanent income hypothesis in row 3 , as contrasted with the weak evidence in row 2. Campbell (1987) also rejected the permanent income hypothesis more strongly when he included five lags of income growth.

17 This finding contrasts with the positive results for stock prices reported by Hall (1978) and others. However close inspection of Hall's stock price regression (his equation (8), on p.984) suggests that almost all the explanatory power comes from the first lagged stock price change. When we include the first lag, we also find strong predictive power from stock price changes; but for the reasons discussed above, we regard this as an illegitimate test of the permanent income model. 
report these in rows 6 and 7 of Table 1 . The instruments are jointly significant for consumption growth at the 1.28 and 0.18 levels. The parameter $\lambda$ is estimated at 0.713 in row 6 (with a $t$ of 2.94 , significant at the 0.48 level), and at 0.615 in row 7 (with a $t$ of 4.49 , significant at less than the 0.18 level).

The last two rows of the table report restricted error-correction models for consumption and income. Row 8 has lags of consumption growth, income growth and the $\log$ consumption-income ratio as instruments; row 9 adds lagged interest rate changes. The results are broadly consistent with those in earlier rows.

Table 1 also tests the overidentifying restrictions of our model (1) on the unrestricted system (2). The test results are reported in the last column of the table; there is no evidence against our restrictions anywhere in this column ${ }^{18}$.

While this is reassuring, we should note that some other features of the results are puzzling. In laying out our model, we argued that one would expect a positive correlation between $\Delta y_{t}$ and $\epsilon_{t}$; this would bias upwards the OLS estimates of $\lambda$, and would give a smaller $R^{2}$ for the regression of consumption growth on instruments than for the regression of income growth on instruments. In fact, in Table 1 we find that our instrumental variables procedure always estimates $\lambda$ to be larger than the OLS estimate of 0.328 , and in three out of eight cases we find that the

18 Deaton's (1986) model, which is our equation (1) with once lagged cansumption growth replacing contemporaneous income growth, would cause us to reject the restrictions of our model when varlables predicting once lagged consumption growth are included in the instrument set. We regard these results as preliminary evidence that Deaton's model does not explain our findings. 
adjusted $R^{2}$ in the consumption equation is larger than the adjusted $R^{2}$ in the income equation. Consumption growth is surprisingly predictable, given the predictability of income growth.

One possible explanation for this pattern of results is that some of the factors which require us to lag our instruments twice, also reverse the presumption that $\Delta y_{t}$ and $\epsilon_{t}$ are positively correlated. For example measurement error in income, uncorrelated with our instruments, could bias downward the oLS estimate of $\lambda$ and reduce the $R^{2}$ in a regression of income growth on instruments, while not affecting the instrumental variables estimates of $\lambda$. We regard this explanation as a tentative one, however.

Summarizing table 1 , we have found strong evidence against the permanent income hypothesis. The results from our instrumental variables test are particularly unfavorable to the permanent income model. When we use instruments which are jointly significant for predicting income growth at the 58 level or better, we get estimates of $\lambda$, the fraction of the population which consumes its current income, in the range 0.35 to 0.65 . These estimates are always strongly significant even though we have lagged the instruments two periods instead of one. The overidentifying restrictions of our model are not rejected at any reasonable significance level.

In Table 2A we extend our sample period backwards to 1949 . It turns out that the addition of the Korean War to the sample has a powerful effect on our results. The fifth and sixth lags of income now have strong predictive power for consumption growth (row 3 ), but the coefficients do not obey the restrictions of our model (1); the parameter 
$\lambda$ is estimated small, negative and insignificant, and the test of our model in the last column rejects at the 0.38 level. Lagged interest rates give estimates of $\lambda$ which are comparable to those in Table 1 , but in general there is much less evidence in 1949-85 that predictable consumption growth is associated with predictable income growth.

It is remarkable that adding only four years of data can have such a large effect on our results. Upon inspecting the data, we found two very unusual observations for income growth. Disposable income grew 6.58 (268 at an annualized rate) in 1950:1, and 4.68 (188 at an annualized rate) in 1975:2. The latter episode was due to a temporary tax rebate (Blinder and Deaton 1985).

In Table $2 B$ we report the results of a simple experiment to see whether our 1949-85 results are dominated by the first quarter of 1950 . We set consumption and income growth for that quarter equal to their means for the 1949.85 period, and repeat Table $2 \mathrm{~A}^{19}$. The results are reassuring. The ability of the fifth and sixth lags of income growth to predict consumption growth is greatly reduced, the point estimates of $\lambda$ are much closer to those in Table 1 and are often statistically significant, and the model (1) is rejected at the 58 level only in row 5 . We also checked that the Table 1 results are not dominated by the data from 1975:2. Setting the 1975:2 observations to their 1953-85 sample means has only a marginal effect on the Table 1 results. The biggest effect is in row 2 , where the estimate of $\lambda$ falls to 0.264 with a

19 This sets the influence of $1950: 1$ to zero. It is not equivalent to adding a 1950:1 dumny to equation (1), since 1950:1 observations appear in the instrument set as well as on the left and right hand sides of equation (1). 
standard error of 0.215 . All the other rows are essentially unaffected 20 .

As a final check on our results, we split the 1953-85 sample into two even subsamples, 1953:1-1969:2 and 1969:3-1985:4. Results for selected sets of instruments are reported in Table 3 . There is a striking contrast between the two subsamples. In the first, income growth is essentially unpredictable using any of our instruments; consequently, it is impossible to identify the parameter $\lambda$ with any precision or to reject the permanent income hypothesis. In the second subsample, by contrast, we can achieve adjusted $R^{2}$ statistics for consumption and income growth of about 258 using five instruments, and the permanent income hypothesis is strongly rejected. Our model (1) is not rejected, indicating that predictable consumption growth is highly correlated with predictable income growth in the $1969-85$ period.

20 The $\lambda$ estimates are: row $30.465(0.188)$; row $40.369(0.142)$; row $50.504(0.134)$; row $60.747(0.247)$; row $70.641(0.143)$; row 8 $0.348(0.110)$; row $0.452(0.098)$. 


\section{Monte Carlo Results}

The evidence in the last section suggests that postwar United States data can reject the permanent income hypothesis. This section presents some Monte Carlo results with two purposes in mind. First, we want to examine the small sample distribution of our test statistics. The problem of small sample bias has been a serious one in tests of the permanent income hypothesis (Mankiw and Shapiro 1985). Monte Carlo experiments can help protect empirical researchers from excessive reliance on asymptotic distribution theory.

Second, we want to shed light on a particular aspect of the results. We found that the hypothesis tests based on the values of $\lambda$ estimated by instrumental variables imply stronger rejections of the permanent income hypothesis than do the hypothesis tests based on oLS estimation of the unrestricted reduced forms. For example, in Row 3 of Table 1, the random walk of consumption is rejected at only the 16.58 level in the unrestricted reduced form. But the t-statistic on $\lambda$ is 3.15 , indicating a rejection at the 0.28 level. We will reconcile these results by showing that if our alternative hypothesis is correct, the instrumental variables test is more powerful than the unrestricted test.

In Table 4 we report the results of a simple Monte Carlo experiment. We generated 500 data sets, each with 125 observations, from the following process:

(4) $\Delta y_{t}=u_{1 t}+u_{2 t}+u_{3 t}$

$$
\Delta c_{t}=\lambda \Delta y_{t}+(1-\lambda) u_{1 t} .
$$


Here $u_{1 t}, u_{2 t}$ and $u_{3 t}$ are normal random variables, serially uncorrelated and uncorrelated with each other. Current and lagged values of $u_{2 t}$ are used as instruments. By choosing $\lambda=0, \operatorname{Var}\left(u_{1 t}\right)-0.33, \operatorname{Var}\left(u_{2 t}\right)=0.1$, and $\operatorname{Var}\left(u_{3 t}\right)=1-0.33-0.1=0.57$, we obtain data with the following properties in the population. First, the instruments have no explanatory power for consumption growth. Second, the true coefficient in an ols regression of $\Delta c_{t}$ on $\Delta y_{t}$ is 0.33 , and the true $R^{2}$ of this regression is also 0.33. Finally, the instruments explain 108 of the variation in $\Delta y_{t}$. Our artificial data thus match some basic moments of the actual U.S. data, and satisfy Hall's "random walk" condition 21.

The first panel of Table 4 shows what happens when we apply our methods to these data. In the first row of the panel, we use one instrument, $u_{2 t} ;$ in the second row, we use three instruments, $u_{2 t}$ through $u_{2, t-2}$; and so on up to 15 instruments. Of course, given the data generation process (4), only the first instrument has explanatory power for $\Delta y_{t}$ in the population. The table reports the empirical mean estimate of $\lambda$ across the 500 data sets, and the empirical mean standard error. It also reports the fraction of the data sets for which oLs $5 \%$ and 18 tests, and instrumental variables 58 and 18 tests, reject the null hypothesis.

When only one instrument is used, Table 4 shows that the OLS and instrumental variables tests give very similar results. Both reject the null at the 58 level about 58 of the time, and at the 18 level about 18 of the time. The mean instrumental variables estimate of $\lambda$ is very close

21 These data do not satisfy the permanent income hypothesis because the "consumption" process violates the intertemporal budget constraint. For the purpose of evaluating our econometric methods, we believe that this feature of the artificial data is relatively unimportant. 
to zero.

As the number of instruments increases, however, the behavior of the instrumental variables test diverges from that of the oLS test. The OLS test tends to reject somewhat less frequently than it should, while the instrumental variables test starts to reject much too frequently. With three instruments, the true size of the instrumental variables test is about twice the theoretical size; with five instruments, the true size of a 58 instrumental variables test is about 158 and the true size of a 18 test is about 5\%. With 10 or 15 instruments, the problem of excessive rejection becomes extreme. The mean estimate of $\lambda$ increases accordingly, and reaches 0.184 when 15 instruments are used.

The reason for this bias in the instrumental variables test is presumably that the first stage regression of $\Delta c_{t}$ and $\Delta y_{t}$ on instruments tends to "overfit" in finite samples 22 . Since $\Delta c_{t}$ and $\Delta y_{t}$ are correlated, this tends to give a nonzero coefficient when the fitted value of $\Delta c_{t}$ is regressed on the fitted value of $\Delta y_{t}$ in the second stage of the instrumental variables procedure. In the extreme case in which one used as many instruments as there are observations, the instrumental variables estimate of $\lambda$ would be the ols coefficient of $\Delta c_{t}$ on $\Delta y_{t}$, which is about 0.33 in the U.S. data and is exactly 0.33 in the artificial data.

The last colum in Part A of Table 4 presents the correct critical values for the IV test. With three instruments, a t-statistic of 2.44 is necessary for a valid test at the 58 level. With five instruments, a

22 The same overfitting affects the ols test, but there it is offset by the increasing degrees of freedom of the test statistic. 
critical value of 2.72 is required. These empirical critical values provide one way to reduce reliance on the asymptotic distribution.

These results imply that one must be careful not to use too many instruments in testing the permanent income model ${ }^{23}$. But they cannot explain the strong rejections of the model we obtain in Table 1 using moderate numbers of instruments. In row 3 of Table 1, for example, the t-statistic on $\lambda$ is 3.15 , using five instruments. In row 5 the $t$ statistic is 4.17 using five instruments. Adjusting for the bias we find in Table 3 weakens these results somewhat, but the permanent income model is still easily rejected at the traditional 58 level.

In the second panel of Table 4, we compare the power of the OLS and instrumental variables procedures against the alternative that $\lambda$ is nonzero. We set $\lambda$ equal to 0.25 , keeping the moments of the shocks in (4) the same as before. We use the empirical critical values for the IV test. We find that the instrumental variables procedure rejects the false null hypothesis that $\lambda$ equals zero much more frequently than the OLS procedure. The difference is striking even when only one instrument is used, and it increases with the number of instruments ${ }^{24}$. Using three instruments, for example, the instrumental variables test rejects at the

23 The early literature on instrumental variables estimation recognized the dangers of using too many instruments; Sargan (1958), for example, recommended the use of only three instruments in samples of typical size. But the point seems to have been forgotten in some recent work testing rational expectations orthogonality restrictions.

24 It is puzzling that the instrumental variables test tends to reject more frequently as we increase the number of instruments, even though the additional instruments have no true explanatory power and we have corrected the size of the test empirically. This appears to be a small sample effect; we did not find it present to nearly the same degree when we ran a small Monte Carlo experiment with 500 observations for each run. 
18 level 328 of the time while the OLS test rejects at this level only 58 of the time. We conclude that the instrumental variables test rejects more strongly than the OLS test in Table 1 primarily because of its greater power to detect this kind of deviation from the permanent income model. 


\section{Generalizations of the Permanent Income Hypothesis}

Our evidence in Section 3 suggests that the aggregate data are not consistent with the permanent income hypothesis. Moreover, the departure from the hypothesis is substantively large: approximately 408 or 508 of income accrues to individuals who consume their current income rather than their permanent income. The purpose of this section is to examine whether generalizations of the permanent income hypothesis along some dimension can explain these findings.

\subsection{Changes in the Real Interest Rate}

Hall's (1978) "random walk" theorem for consumption rests on the crucial assumption that the real interest rate is constant. Any rejection of the theory might be attributable to the failure of this assumption. For example, Michener (1984) shows how variation through time in the real interest rate can make consumption appear excessively sensitive to income, even though individuals intertemporally optimize in the absence of borrowing constraints. It is therefore important to examine whether the departure from the theory documented above is an artifact of the assumed constancy of the real interest rate.

The generalization of the consumer's Euler equation to allow for changes in the real interest rate is now well-known (Grossman and Shiller 1981, Mankiw 1981, Hansen and Singleton 1983, Hall 1987). The log-linear version of the Euler equation is

(5) $\Delta c_{t}=\mu+(1 / \alpha) r_{t}+\epsilon_{t}$,

where $r_{t}$ is the real interest rate contemporaneous with $\Delta c_{t}$, and as 
before the ercor term $\epsilon_{t}$ may be correlated with $r_{t}$ but is uncorrelated with lagged variables. According to (5), high ex ante real interest rates should be associated with rapid growth of consumption. If higher income growth is associated with higher real interest rates, the deviation from the permanent income hypothesis documented above could be explained by this more general model.

To examine this possibility, we consider a more general model in which a fraction $\lambda$ of income goes to individuals who consume their current income and the remainder goes to individuals who satisfy the general Euler equation (5). We estimate by instrumental variables

(6) $\Delta c_{t}=\mu+\lambda \Delta y_{t}+\theta r_{t}+\epsilon_{t}$

where $\theta=(1-\lambda) / \alpha$. We thus include the actual income growth and the ex post real interest rate in the equation, but instrument using twice lagged variables. The nominal interest rate we use is the average threemonth treasury bill rate over the quarter, the price index is the deflator for consumer nondurables and services, and we assume that there is a 308 marginal tax rate on interest ${ }^{25}$. The results are in Table 5 .

We find no evidence that the ex ante real interest rate is associated with the growth rate of consumption. The coefficient on the real interest rate is consistently less than its standard error. Moreover, the coefficient on current income remains substantively and statistically significant. In contrast to the suggestion of Michener (1984), the of zero.

25 We obtained similar results when we assumed a marginal tax rate 
excess sensitivity of consumption to income cannot be explained by fluctuations in the real interest rate.

The regressions of Table 5 are similar to those of Hall (1987), except that they include the change in income as well as the ex post real interest rate. When we omitted the change in income and estimated equation (5), we found slightly larger, but still fairly small values for the coefficient on the real interest rate: 0.202 (with a standard error of 0.115$)$ for the instruments in row 2 of Table $5,0.140(0.117)$ for the instruments in row 3 of Table 5 , and $0.180(0.119)$ for the instruments in row 4 of Table 5 .

Hall interprets evidence of this sort as indicating that consumers are extremely reluctant to substitute intertemporally $(1 / \alpha$ is very small, and $\alpha$ is very large). We note, however, that if equation (5) is properly specified one should be able to estimate it with either consumption growth or the real interest rate as the dependent variable. When the real interest rate is the dependent variable, the coefficient estimated by instrumental variables should be $\alpha$ rather than $(1 / \alpha)$. On reversing the regressions, we found coefficients of $1.469(0.503), 0.825(0.337)$, and $0.772(0.287)$ respectively. While these estimates are statistically significant, and larger than those from the Hall regressions, one cannot conclude from them that $\alpha$ is very large.

The reason why we obtain such different results when we renormalize equation (5) is that the data reject the overidentifying restrictions of (5). The reversed regressions are all rejected at the $0.1 \%$ level or better, indicating that there are predictable movements in real interest 
rates which are not associated with predictable consumption growth ${ }^{26}$. One should be cautious in interpreting estimates from such a system. Our model (1), however, is not sensitive to renormalization and we do not reject its restrictions in either its original or its renormalized form.

\subsection{Nonseparabilities in the Utility Function}

The "random walk" theorem for consumption will also fail if consumption is not separable in the utility function from other goods. With constant real interest rates, the marginal utility of consumption is a martingale even under non-separability. That is, it is still true that

(7) $E_{t} U^{\prime}\left(C_{t+1}, x_{t+1}\right)=\gamma U^{\prime}\left(C_{t}, X_{t}\right)$

for some constant $\gamma$. Yet predictable changes in the other good X must lead to predictable changes in consumption to maintain the martingale property of marginal utility. If changes in $X$ are correlated with changes in income, non-separability could in principle explain the apparent excess sensitivity of consumption to income documented in Section 3 .

We test for non-separability in a very simple way. We include the change in $\log \mathrm{X}$ as an additional right-hand side variable in our equation. This functional form can be formally justified if the utility function is Cobb-Douglas (Bean 1986) or as a $\log$ linear approximation to

26 Both the specifications (5) and (6) are rejected when the regressions are reversed to make the real interest rate the dependent variable, but are not rejected when the real rate is an explanatory variable. The reason for this is that the real rate is given a coefficient of approximately zero when it is an explanatory variable, so the predictable movements of the real interest rate do not enter intc the fitted value or residual of the equation. 
a more general specification. As before, we estimate the equation using twice-lagged instrumental variables.

Various non-separabilities have been proposed. Mankiw, Rotemberg, and Summers (1985) and Eichenbaum, Hansen, and Singleton (1987) consider nonseparability between consumption and labor supply. In Table 6 we include the change in log labor supply as a right hand side vartable with coefficient $\theta$. Labor supply is measured as per capita man-hours in nonagricultural establishments. The results suggest no important nonseparability between consumption and labor supply. Even though there is substantial predictable variation in the quantity of labor supplied, it apparently does not lead to predictable changes in consumption.

Bernanke (1985) and Startz (1987) propose that the marginal utility of nondurable goods may be affected by the stock of consumer durable goods. In Table 7 we enter this stock as the $X$ variable. The stock of consumer durables during a quarter is measured as the average of the end-ofquarter stock and the previous end-of-quarter stock ${ }^{27}$. (Other timing assumptions lead to similar results.) We find substantial predictable changes in the stock of durables, but no evidence that these changes coincide with predictable changes in consumption.

It is often suggested that changes in government purchases of goods and services affect the marginal utility of private consumption (Bailey 1971, Kormendi 1983, Aschauer 1985). Indeed, Aschauer suggests that allowing for such an effect can save the consumption Euler equation from a statistical rejection. In Table 8 we examine this possibility by

27 We constructed an end-of-quarter stock series from the annual stock at the beginning of the sample period and the series on consumer durable purchases, assuming a depreciation rate of $6 \%$ per quarter. 
entering the change in the log of total government purchases per capita as a right-hand side variable. Again, we find no evidence of nonseparability in the utility function. Moreover, the estimate of $\lambda$ we obtain remains statistically and substantively significant. In contrast to Aschauer, we find that non-separability between private and public purchases does not improve the performance of the consumption Euler equation. 


\section{Conclusions}

Our analysis of United States postwar quarterly data leads us to the following conclusions:

(1) There is modest evidence against the implication of the permanent income hypothesis that changes in consumption are unforecastable. When the change in $\log$ consumption is regressed on its own lags two through six in the 1953-85 period, the null hypothesis that all the coefficients are zero can be rejected at the 0.68 level. While the adjusted $R^{2}$ of this regression is $\operatorname{small}(98)$, a small $\mathrm{R}^{2}$ should not be viewed as supportive of the permanent income hypothesis, since the $R^{2}$ of the comparable regression for the change in disposable income is also very small.

(2) The evidence against the permanent income model comes primarily from the second half of our sample period, 1969-85. In the first half of the sample, 1953-69, the data have little power to discriminate between models because income growth is essentially unpredictable.

(3) The forecastability of consumption can be explained by a model in which a fraction $\lambda$ of income goes to individuals who consume their current income rather than their permanent income. This more general model is not statistically rejected. Our estimates suggest that $\lambda$ is approximately 0.4 or 0.5 , indicating a substantial departure from the permanent income hypothesis.

(4) The result that consumption tracks income too closely cannot be explained by the time-averaged nature of the data, by short delays in publication of aggregate statistics, or by partial durability of goods labelled "nondurable" in the National Income Accounts. Our test of the 
permanent income model is robust to all these problems because, in common with Hall (1987) but in contrast with much of the rest of the literature, we lag our instruments by two quarters instead of one.

(5) Our results cannot be explained by appealing to more general versions of the permanent income hypothesis. We have allowed for changes in the real interest rate, but we find no evidence that changes in the real interest rate lead to predictable changes in consumption. We have also allowed for non-separability in the utility function between consumption and other goods--labor supply, consumer durables, and government purchases--but we find no evidence for any such nonseparability. 
TABLE 1

BASIC MODEL, 1953-85

\begin{tabular}{|c|c|c|c|c|c|}
\hline Row & Instruments & $\begin{array}{l}\text { First-stage } \\
\Delta c \text { equation }\end{array}$ & $\begin{array}{l}\text { regressions } \\
\Delta y \text { equation }\end{array}$ & $\begin{array}{c}\lambda \text { estimate } \\
(\text { s.e.) }\end{array}$ & $\begin{array}{l}\text { Test of } \\
\text { restrictions }\end{array}$ \\
\hline 1 & None (OLS) & $\cdots$ & $\ldots$ & $\begin{array}{c}0.328 \\
(0.041)\end{array}$ & $\cdots$ \\
\hline 2 & $\Delta y_{t-2}, \cdots, \Delta y_{t-4}$ & $\begin{array}{l}-0.003 \\
(0.460)\end{array}$ & $\begin{array}{c}0.021 \\
(0.124)\end{array}$ & $\begin{array}{c}0.379 \\
(0.196)\end{array}$ & $\begin{array}{l}-0.023 \\
(0.988)\end{array}$ \\
\hline 3 & $\Delta y_{t-2}, \ldots, \Delta y_{t-6}$ & $\begin{array}{c}0.022 \\
(0.165)\end{array}$ & $\begin{array}{c}0.043 \\
(0.062)\end{array}$ & $\begin{array}{c}0.477 \\
(0.151)\end{array}$ & $\begin{array}{l}-0.035 \\
(0.962)\end{array}$ \\
\hline 4 & $\Delta c_{t-2}, \cdots, \Delta c_{t-4}$ & $\begin{array}{c}0.022 \\
(0.121)\end{array}$ & $\begin{array}{c}0.050 \\
(0.024)\end{array}$ & $\begin{array}{c}0.406 \\
(0.154)\end{array}$ & $\begin{array}{l}-0.012 \\
(0.486)\end{array}$ \\
\hline 5 & $\Delta c_{t-2}, \ldots, \Delta c_{t-6}$ & $\begin{array}{c}0.089 \\
(0.006)\end{array}$ & $\begin{array}{c}0.088 \\
(0.006)\end{array}$ & $\begin{array}{c}0.526 \\
(0.126)\end{array}$ & $\begin{array}{l}-0.016 \\
(0.555)\end{array}$ \\
\hline 6 & $\Delta i_{t-2}, \ldots, \Delta i_{t-4}$ & $\begin{array}{c}0.062 \\
(0.012)\end{array}$ & $\begin{array}{c}0.025 \\
(0.099)\end{array}$ & $\begin{array}{c}0.713 \\
(0.242)\end{array}$ & $\begin{array}{l}-0.016 \\
(0.601)\end{array}$ \\
\hline 7 & $\Delta i_{t-2}, \cdots, \Delta i_{t-6}$ & $\begin{array}{c}0.122 \\
(0.001)\end{array}$ & $\begin{array}{c}0.087 \\
(0.007)\end{array}$ & $\begin{array}{c}0.615 \\
(0.137)\end{array}$ & $\begin{array}{l}-0.025 \\
(0.771)\end{array}$ \\
\hline 8 & $\begin{array}{c}\Delta y_{t-2}, \ldots, \Delta y_{t-4}, \\
\Delta c_{t-2}, \ldots, \Delta c_{t-4}, \\
c_{t-2}-y_{t-2}\end{array}$ & $\begin{array}{c}0.010 \\
(0.305)\end{array}$ & $\begin{array}{c}0.089 \\
(0.011)\end{array}$ & $\begin{array}{c}0.351 \\
(0.110)\end{array}$ & $\begin{array}{l}-0.040 \\
(0.914)\end{array}$ \\
\hline 9 & $\begin{array}{c}\Delta y_{t-2}, \ldots, \Delta y_{t-4} \\
\Delta c_{t-2}, \ldots, \Delta c_{t-4} \\
\Delta i_{t-2}, \ldots, \Delta i_{t-4} \\
c_{t-2}^{-y_{t-2}}\end{array}$ & $\begin{array}{c}0.080 \\
(0.031)\end{array}$ & $\begin{array}{c}0.115 \\
(0.007)\end{array}$ & $\begin{array}{c}0.454 \\
(0.099)\end{array}$ & $\begin{array}{l}-0.031 \\
(0.715)\end{array}$ \\
\hline
\end{tabular}

Notes: The statistics in columns 3,4 and 6 are adjusted $R^{2}$ values, and significance levels for tests of the hypothesis that all coefficients except the constant are zero (in parentheses). The statistics in column 5 are the instrumental variables estimate of $\lambda$, with an asymptotic standard error (in parentheses). 
TABLE 2A

BASIC MODEL, 1949-85

\begin{tabular}{|c|c|c|c|c|c|}
\hline Row & Instruments & $\begin{array}{l}\text { First-stage } \\
\Delta c \text { equation }\end{array}$ & $\begin{array}{l}\text { regressions } \\
\Delta y \text { equation }\end{array}$ & $\begin{array}{c}\lambda \text { estimate } \\
(\text { s.e. })\end{array}$ & $\begin{array}{c}\text { Test of } \\
\text { restrictions }\end{array}$ \\
\hline 1 & None (OLS) & $\ldots$. & $\ldots$ & $\begin{array}{c}0.217 \\
(0.040)\end{array}$ & $\ldots$ \\
\hline 2 & $\Delta y_{t-2}, \cdots, \Delta y_{t-4}$ & $\begin{array}{l}-0.009 \\
(0.639)\end{array}$ & $\begin{array}{c}0.055 \\
(0.012)\end{array}$ & $\begin{array}{l}-0.095 \\
(0.176)\end{array}$ & $\begin{array}{l}-0.013 \\
(0.565)\end{array}$ \\
\hline 3 & $\Delta y_{t-2}, \ldots, \Delta y_{t-6}$ & $\begin{array}{c}0.083 \\
(0.005)\end{array}$ & $\begin{array}{c}0.042 \\
(0.050)\end{array}$ & $\begin{array}{l}-0.033 \\
(0.166)\end{array}$ & $\begin{array}{c}0.077 \\
(0.003)\end{array}$ \\
\hline 4 & $\Delta c_{t-2}, \ldots, \Delta c_{t-4}$ & $\begin{array}{c}0.004 \\
(0.307)\end{array}$ & $\begin{array}{c}0.018 \\
(0.130)\end{array}$ & $\begin{array}{c}0.153 \\
(0.208)\end{array}$ & $\begin{array}{c}0.005 \\
(0.157)\end{array}$ \\
\hline 5 & $\Delta c_{t-2}, \ldots, \Delta c_{t-6}$ & $\begin{array}{c}0.007 \\
(0.309)\end{array}$ & $\begin{array}{c}0.011 \\
(0.247)\end{array}$ & $\begin{array}{c}0.253 \\
(0.191)\end{array}$ & $\begin{array}{c}0.002 \\
(0.255)\end{array}$ \\
\hline 6 & $\Delta i_{t-2}, \cdots, \Delta i_{t-4}$ & $\begin{array}{c}0.045 \\
(0.022)\end{array}$ & $\begin{array}{c}0.014 \\
(0.170)\end{array}$ & $\begin{array}{c}0.694 \\
(0.306)\end{array}$ & $\begin{array}{l}-0.016 \\
(0.712)\end{array}$ \\
\hline 7 & $\Delta i_{t-2}, \cdots, \Delta i_{t-6}$ & $\begin{array}{c}0.088 \\
(0.003)\end{array}$ & $\begin{array}{c}0.053 \\
(0.027)\end{array}$ & $\begin{array}{c}0.604 \\
(0.176)\end{array}$ & $\begin{array}{l}-0.027 \\
(0.888)\end{array}$ \\
\hline 8 & $\begin{array}{c}\Delta y_{t-2}, \ldots, \Delta y_{t-4} \\
\Delta c_{t-2}, \ldots, \Delta c_{t-4} \\
c_{t-2}-y_{t-2}\end{array}$ & $\begin{array}{c}0.003 \\
(0.387)\end{array}$ & $\begin{array}{c}0.149 \\
(0.000)\end{array}$ & $\begin{array}{c}0.074 \\
(0.097)\end{array}$ & $\begin{array}{c}0.004 \\
(0.270)\end{array}$ \\
\hline 9 & $\begin{array}{c}\Delta y_{t-2}, \ldots, \Delta y_{t-4}, \\
\Delta c_{t-2}, \ldots, \Delta c_{t-4}^{\prime} \\
\Delta i_{t-2}, \ldots, \Delta t_{t-4} \\
c_{t-2} y_{t-2}\end{array}$ & $\begin{array}{c}0.047 \\
(0.086)\end{array}$ & $\begin{array}{c}0.153 \\
(0.001)\end{array}$ & $\begin{array}{c}0.154 \\
(0.089)\end{array}$ & $\begin{array}{c}0.046 \\
(0.059)\end{array}$ \\
\hline
\end{tabular}

Notes: See notes to Table 1. 
TABLE 2B

\section{BASIC MODEL, 1949-85 \\ 1950:1 OBSERVATION REMOVED}

Row Instruments

First-stage regressions $\Delta c$ equation $\Delta y$ equation
$\lambda$ estimate
(s.e.)

Test of restrictions
1 None (OLS)

$2 \Delta y_{t-2}, \cdots, \Delta y_{t-4}$

$3 \quad \Delta y_{t-2}, \cdots, \Delta y_{t-6}$

$4 \Delta c_{t-2}, \ldots, \Delta c_{t-4}$

0.012
$(0.185)$

$$
\begin{aligned}
& -0.014 \\
& (0.787)
\end{aligned}
$$

$$
\begin{gathered}
0.033 \\
(0.082)
\end{gathered}
$$

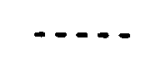

$$
\begin{gathered}
0.251 \\
(0.045)
\end{gathered}
$$

$$
\begin{gathered}
0.013 \\
(0.174)
\end{gathered}
$$

0.256

(0.246)

$-0.020$

$(0.913)$

$$
\begin{gathered}
0.006 \\
(0.324)
\end{gathered}
$$
0.499
$(0.250)$

0.005

$(0.218)$

$5 \quad \Delta c_{t-2}, \cdots, \Delta c_{t-6}$
0.013
$(0.225)$
0.061
$(0.018)$
0.057
(0.010)
0.240
(0.163)

0.004

(0.162)

0.288
$(0.148)$

$-0.003$

$(0.023)$

$6 \quad \Delta i_{t-2}, \ldots, \Delta i_{t-4}$

$\begin{array}{cc}0.045 & 0.020 \\ (0.023) & (0.117)\end{array}$

0.719

(0.298)

$-0.016$

(0.683)

$7 \Delta i_{t-2}, \cdots, \Delta i_{t-6}$
0.089
$(0.003)$
0.073
$(0.008)$

0.609
$(0.166)$

$-0.025$

$(0.845)$

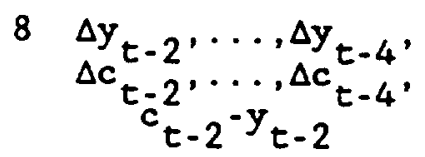

$9 \Delta y_{t-2}, \ldots, \Delta y_{t-4}$,

$$
\begin{aligned}
& \Delta y_{t-2}, \ldots, \Delta y_{t-4} \\
& \Delta c c_{t-2}, \ldots, c_{t-4} \\
& \Delta i_{t-2}, \ldots, \Delta i_{t-4} \\
& c_{t-2}^{-y_{t-2}}
\end{aligned}
$$

$$
-0.007
$$

(0.539)

0.040

(0.113)
0.123

$(0.003)$

0.212

(0.118)

$(0.003)$

$(0.118)$

0.327

(0.106)
$-0.022$

$(0.678)$

$-0.008$

$(0.444)$

Notes: See notes to Table 1. 
TABLE 3

BASIC MODEL, 1953:1-1969:2 AND 1969:3-1985:4

Row Instruments

\section{A. $1953: 1-1969: 2$}

1 None (OLS)

$2 \Delta y_{t-2}, \cdots, \Delta y_{t-6}$

0.003
$(0.386)$

$-0.061$

$(0.931)$

0.233

$(0.551)$

0.472

$(0.072)$

$3 \quad \Delta c_{t-2}, \cdots, \Delta c_{t-6}$

-0.031
$(0.673)$

$-0.059$

$(0.914)$

0.752

$(0.535)$

0.014

(0.315)

0.638

(0.252)

0.016
$(0.301)$

$(0.315)$

B. $1969: 3-1985: 4$

5 None (OLS)

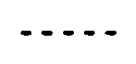

$-\cdots$

0.264

(0.048)

$6 \Delta y_{t-2}, \ldots, \Delta y_{t-6}$

0.077
$(0.082)$

0.080
$(0.076)$

0.447

(0.137)

$-0.070$

$(0.082)$

$(0.137)$

$(0.936)$

$7 \Delta c_{t-2}, \ldots, \Delta c_{t-6}$
0.239
.0 .237
(0.002)
$(0.001)$

0.411

(0.095)

0.012

0.092

$(0.058)$

0.579

(0.155)

$(0.212)$

$8 \quad \Delta i_{t-2}, \ldots, \Delta i_{t-6}$

0.235
$(0.002)$

$(0.058)$

\author{
(0.155)
}

$-0.040$

(0.619)

0.036
$(0.122)$

$-0.046$

$(0.690)$

$-0.039$

(0.611) 
TABLE 4

MONTE CARLO RESULTS

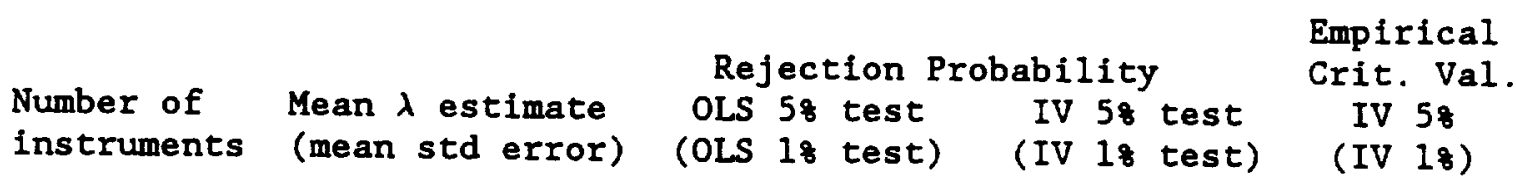

A. True $\lambda=0,00$

$\begin{array}{ccccc}1 & -0.043 & 5.08 & 5.68 & 1.99 \\ & (0.206) & (0.68) & (1.88) & (2.87) \\ 3 & 0.028 & 6.48 & 11.08 & \\ & (0.170) & (1.28) & (4.08) & (3.54) \\ 5 & 0.071 & & & \\ & (0.146) & (1.08) & 15.4 & 2.72 \\ 10 & 0.143 & 3.68 & (7.0) & (3.58) \\ & (0.118) & (0.48) & 32.28 & 3.34 \\ 15 & 0.184 & 2.68 & (17.88) & (4.26) \\ & (0.103) & (0.68) & 49.68 & 3.78 \\ & & & (27.28) & (4.97)\end{array}$

B. True $\lambda=0.25$

$\begin{array}{cccc}1 & 0.215 & 30.08 & 47.48 \\ & (0.160) & (10.68) & (31.88) \\ 3 & 0.275 & 20.48 & 55.68 \\ & (0.122) & (5.08) & (32.08) \\ 5 & 0.309 & 15.48 & 63.28 \\ & (0.107) & (5.28) & (40.88) \\ 10 & 0.349 & 9.28 & 69.48 \\ & (0.091) & (3.08) & (46.68) \\ 15 & 0.391 & 8.88 & 84.28 \\ & (0.077) & (1.48) & (58.68)\end{array}$


TABLE 5

REAL INTEREST RATES, 1953-85

$$
\begin{aligned}
& \text { Row Instruments } \\
& \text { First-stage regressions } \lambda \quad \theta \quad \text { Test of } \\
& \begin{array}{lllll}
\Delta c & \Delta y & r & (s . e .) & \text { (s.e.) restrictions }
\end{array} \\
& 1 \text { None (OLS) }
\end{aligned}
$$

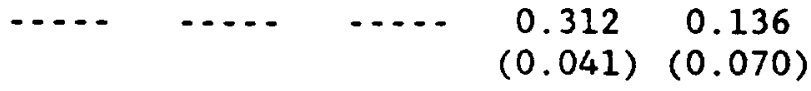

$$
\begin{aligned}
& 2 \Delta_{t-2}, \cdots, \Delta y_{t-4} \\
& \begin{array}{llllll}
0.031 & 0.039 & 0.484 & 0.413 & 0.051 & -0.015
\end{array}
\end{aligned}
$$

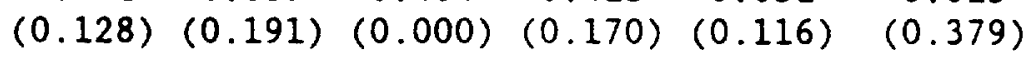

$$
\begin{aligned}
& 3 \begin{array}{r}
\Delta c_{t-2}, \ldots, \Delta c_{t-4} \\
r_{t-2}, \ldots, r_{t-4}^{t}
\end{array} \\
& \begin{array}{llllll}
0.046 & 0.049 & 0.467 & 0.451 & 0.049 & -0.010
\end{array} \\
& (0.066)(0.057)(0.000)(0.143)(0.106) \quad(0.314) \\
& 4 \quad \Delta i_{t-2}, \ldots, \Delta i_{t-4} \\
& \begin{array}{llllll}
0.077 & 0.026 & 0.448 & 0.668 & -0.022 & -0.022
\end{array} \\
& \begin{array}{lllll}
(0.015)(0.155)(0.000)(0.214) & (0.141) & (0.515)
\end{array} \\
& \text { Row Instruments } \\
& \text { First-stage regressions } \lambda \quad \theta \quad \text { Test of } \\
& \begin{array}{lllll}
\Delta c & \Delta y & \Delta l & (\text { s.e.) } & \text { (s.e.) restrictions }
\end{array} \\
& 1 \text { None (OLS) } \\
& \begin{array}{cccc}
\cdots & \cdots & 0.287 & 0.102 \\
(0.044) & (0.046)
\end{array} \\
& 2 \quad \Delta y_{t-2}, \ldots, \Delta y_{t-4} \\
& \begin{array}{llllll}
-0.006 & 0.025 & 0.139 & 0.380 & 0.037 & -0.046
\end{array} \\
& \begin{array}{llllll}
(0.502) & (0.164) & (0.001) & (0.235) & (0.152) & (0.990)
\end{array} \\
& 3 \begin{array}{ll}
\Delta c_{t-2} & \cdots, \Delta c_{t-4} \\
& \Delta 1_{t-2}, \ldots, \Delta 1_{t-4}^{t}
\end{array} \\
& \begin{array}{cccccc}
0.029 & 0.079 & 0.221 & 0.364 & 0.047 & -0.037 \\
(0.138) & (0.013) & (0.000) & (0.203) & (0.144) & (0.841)
\end{array} \\
& 4 \begin{array}{ll}
\Delta i_{t-2} & \cdots, \Delta i_{t-4} \\
& \Delta 1_{t-2}, \ldots, \Delta 1_{t-4}
\end{array} \\
& \begin{array}{cccccc}
0.086 & 0.062 & 0.150 & 0.497 & 0.087 & -0.028 \\
(0.010) & (0.031) & (0.000) & (0.223) & (0.172) & (0.642)
\end{array}
\end{aligned}
$$


TABLE 7

DURABLE GOODS, 1953-85

Row Instruments

1 None (OLS)

$2 \quad{ }^{\Delta y_{t-2}}{ }_{t-2}, \cdots, \Delta y_{t-4}$
First-stage regressions

$\Delta c$

$\Delta y$
$\Delta d$

$-\cdots$

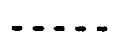

$-\cdots$

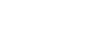

0.31

$(0.041)(0.079)$

$=3 \quad \begin{aligned} & \Delta c_{t-2}, \ldots, \Delta c_{t-4} \\ & \Delta d_{t-2}, \ldots, \Delta d_{t-4}\end{aligned}$

$0.025 \quad 0.054$

$(0.162)(0.046)(0.769)$

$\lambda$

$\theta$ Test of

(s.e.) (s.e.) restrictions

$4 \quad \Delta_{t-2}, \ldots, \Delta d_{t-2}, \ldots, \Delta d_{t-4}$

0.106

$(0.003)(0.054)$

0.752

$0.752 \quad 0.549$

$\begin{array}{cc}0.549 & 0.082 \\ (0.155) & (0.106)\end{array}$

$-0.000$

(0.200)

\section{TABLE 8}

GOVERMMENT SPENDING, 1953-85

Row Instruments

First-stage regressions $\lambda$ $\begin{array}{lllll}\Delta c & \Delta y & \Delta g & (\text { s.e.) } & \text { (s.e.) restrictions }\end{array}$

1 None (OLS)
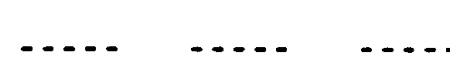

$$
\begin{array}{cc}
0.328 & -0.006 \\
(0.041) & (0.026)
\end{array}
$$

$2 \begin{array}{r}\Delta y_{t-2}, \ldots, \Delta y_{t-4} \\ \Delta g_{t-2}, \ldots, \Delta g_{t-4}\end{array}$

$-0.026$

$(0.843)(0$.

$0.012 \quad 0.067$

0.344

$0.021 \quad-0.044$

$(0.271)(0.024)(0.202)(0.093)(0.979)$

$3 \begin{aligned} & \Delta c_{t-2}, \ldots, \Delta c_{t-4} \\ & \Delta g_{t-2}, \cdots, \Delta g_{t-4}\end{aligned}$

$-0.001$

$(0.427)$

$0.043 \quad 0.046$

0.357

$0.051 \quad-0.035$

$(0.077)(0.065)$

$(0.142)$

$(0.088)$

$(0.797)$

$4 \quad \begin{aligned} & \Delta i_{t-2}, \ldots, \Delta i_{t-4} \\ & \Delta g_{t-2}, \ldots, \Delta g_{t-4}\end{aligned}$

0.040

0.013

0.037

0.664

0.103

$-0.035$

$\begin{array}{llllll}(0.085) & (0.263) & (0.097) & (0.233) & (0.125) & (0.797)\end{array}$ 


\section{Bibliography}

Aschauer, David A., "Fiscal Policy and Aggregate Demand", American Economic Review 75:117-127, March 1985.

Bailey, Martin J., National Income and the Price Level, 2nd edition, McGraw-Hill, New York, 1971.

Bean, Charles R., "The Estimation of 'Surprise' Models and the 'Surprise' Consumption Function", Review of Economic Studies 53:497-516, August 1986.

Bernanke, Ben S., "Adjustment Costs, Durables and Aggregate Consumption", Journal of Monetary Economics 15:41-68, January 1985.

Blinder, Alan S, and Angus S. Deaton, "The Time Series Consumption Function Revisited", Brookings Papers on Economic Activity 2:465-511, 1985 .

Campbe11, John Y., "Does Saving Anticipate Declining Labor Income? An Alternative Test of the Permanent Income Hypothesis", forthcoming Econometrica, 1987.

Campbe11, John Y. and Angus S. Deaton, "Why Is Consumption So Smooth?", unpublished paper, Princeton University, July 1987.

Christiano, Lawrence J., Martin Eichenbaum and David Marshall, "The Permanent Income Hypothesis Revisited", Research Department Working Paper No. 335, Federal Reserve Bank of Minneapolis, March 1987.

Davidson, James E.H. and David F. Hendry, "Interpreting Econometric Evidence: The Behavior of Consumers' Expenditure in the U.K.", European Economic Review 16:177-192, 1981.

Davidson, James E.H., David F. Hendry, Frank Srba and Stephen Yeo, "Econometric Modelling of the Aggregate Time-Series Relationship Between Consumers' Expenditure and Income in the United Kingdom", Economic Journal 88:661-692, December 1978 .

Deaton, Angus S., "Life-cycle Models of Consumption: Is the Evidence Consistent With the Theory?", NBER Working Paper No. 1910, 1986.

DeLong, J. Bradford and Lawrence H. Summers, "The Changing Cyclical Variability of Economic Activity in the United States", in Robert $J$. Gordon ed. The American Business Cycle: Continuity and Change, Chicago: University of Chicago Press, 1986.

Dornbusch, Rudiger and Stanley Fischer, Macroeconomics, 1987.

Eichenbaum, Martin S., Lars Peter Hansen and Kenneth J. Singleton, "A Time Series Analysis of Representative Agent Models of Consumption and Leisure Choice under Uncertainty", NBER Working Paper No. 1981, 1986. 
Engle, Robert F. and C.W.J. Granger, "Co-Integration and ErrorCorrection: Representation, Estimation and Testing", Econometrica 55:251. 276, March 1987.

Fischer, Stanley and Robert C. Merton, "Macroeconomics and Finance: the Role of the Stock Market", in Karl Brunner and Allan H. Meltzer eds., Carnegie-Rochester Conference Series on Public Policy Vol. 21, Ams terdam: North-Holland, 1984.

Flavin, Marjorie A., "The Adjustment of Consumption to Changing Expectations about Future Income", Journal of Political Economy 89:974. 1009, October 1981.

Goodfriend, Marvin, "Information-Aggregation Bias: The Case of Consumption", unpublished paper, Federal Reserve Bank of Richmond, October 1986.

Grossman, Sanford J. and Robert J. Shiller, "The Determinants of the Variability of Stock Market Prices", American Economic Review 71:222-227, May 1981.

Hal1, Robert E., "Stochastic Implications of the Life Cycle-Permanent Income Hypothesis: Theory and Evidence", Journal of Political Economy $86: 971-987$, October 1978 .

Ha11, Robert E., "The Role of Consumption in Economic Fluctuations", in Robert J. Gordon ed., The American Business Cycle: Continuity and Change, Chicago: University of Chicago Press, 1986.

Hal1, Robert E., "Intertemporal Substitution in Consumption", forthcoming Journal of Political Economy, 1987.

Hayashi, Fumio, "The Permanent Income Hypothesis: Estimation and Testing by Instrumental Variables", Journal of Political Economy 90:895916, October 1982.

Hansen, Lars P. and Kenneth J. Singleton, "Stochastic Consumption, Risk Aversion, and the Temporal Behavior of Asset Returns", Journal of Political Economy 91:249-265, April 1983.

Kormendi, Roger C., "Government Debt, Government Spending, and Private Sector Behavior", American Economic Review 73:994-1010, December 1983.

Litterman, Robert B. and Laurence Weiss, "Money, Real Interest Rates and Output: A Reinterpretation of Postwar U.S. Data", Econometrica 53:129-156, January 1985 .

Mankiw, N. Gregory, "The Permanent Income Hypothesis and the Real Interest Raten, Economics Letters 7:307-311, 1981. 
Mankiw, N. Gregory, "Hall's Consumption Hypothesis and Durable Goods", Journal of Monetary Economics 10:417-426, November 1982.

Mankiw, N. Gregory, Julio Rotemberg and Lawrence Summers, "Intertemporal Substitution in Macroeconomics", Quarterly Journal of Economics 100:225-251, February 1985.

Mankiw, N. Gregory and Matthew D. Shapiro, "Trends, Random Walks and Tests of the Permanent Income Hypothesis", Journal of Monetary Economics $16: 165-174,1985$.

Michener, Ron, "Permanent Income in General Equilibrium", Journal of Monetary Economics 13: 297-306.

Nelson, Charles R., "A Reappraisal of Recent Tests of the Permanent Income Hypothesis", Journal of Political Economy 95:641-646, June 1987.

Sargan, J.D., "The Estimation of Economic Relationships Using Instrumental Variables", Econometrica 26:393-415, 1958.

Sims, Christopher A., "Comparison of Interwar and Postwar Cycles: Monetarism Reconsidered", American Economic Review 70:250-257, 1980.

Startz, Richard, "The Stochastic Behavior of Durable and Nondurable Consumption", unpublished paper, University of Washington, December 1986.

Summers, Lawrence H., "Tax Policy, the Rate of Return, and Savings", NBER Working Paper No. 995, September 1982.

West, Kenneth D., "The Insensitivity of Consumption to News About Income", Woodrow Wilson School Discussion Paper No. 119, Princeton University, 1986.

Working, Holbrook, "Note on the Correlation of First Differences of Averages in a Random Chain", Econometrica 28:916-918, October 1960. 